\title{
PROJECTION AND TRUTH IN ETHICS
}

by

JOHN McDOWELL

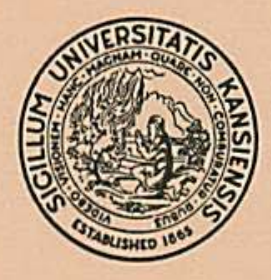

The Lindley Lecture

The University of Kansas

1987 
The E. H. Lindley Memorial Lectureship Fund was established in 1941 in memory of Ernest H. Lindley, Chancellor of the University of Kansas from 1920 to 1939. In February $1941 \mathrm{Mr}$. Roy Roberts, the chairman of the committee in charge, suggested in the Graduate Magazine that

the Chancellor should invite to the University for a lecture or a series of lectures, some outstanding national or world figure to speak on "Values of Living"- just as the late Chancellor proposed to do in his courses "The Human Situation" and "Plan for Living."

In the following June Mr. Roberts circulated a letter on behalf of the Committee, proposing in somewhat broader terms that

The income from this fund should be spent in a quest of social betterment by bringing to the University each year outstanding world leaders for a lecture or series of lectures, yet with a design so broad in its outline that in the years to come, if it is deemed wise, this living memorial could take some more desirable form.

The fund was allowed to accumulate until 1954, when Professor Richard McKeon lectured on "Human Rights and International Relations." The next lecture was given in 1959 by Professor Everett C. Hughes, and has been published by the University of Kansas School of Law as part of his book Students' Culture and Perspectives: Lectures on Medical and General Education. The selection of lecturers for the Lindley series has since been delegated to the Department of Philosophy. 


\title{
PROJECTION AND TRUTH IN ETHICS
}

by

\author{
JOHN MCDOWELL \\ Professor of Philosophy \\ University of Pittsburgh
}

The Lindley Lecture, University of Kansas, October 21, 1987 
(C) Copyright 1988 by Department of Philosophy University of Kansas 


\title{
Projection and Truth in Ethics
}

\author{
John McDowel]
}

1. Projection is what the mind engages in when, as Hume puts the idea, it 'spreads itself on to the external world.' This image certainly seems to fit some ways of thinking and talking that we can be tempted into: consider for instance the confused notion that disgustingness is a property that some things have intrinsically or absolutely, independently of their relations to us-a property of which our feelings of disgust constitute a kind of perception. That this notion is confused is of course no reason to suppose it cannot be true that something is disgusting. But the image of projection, figuring as it does in an explanation of how the confused notion comes about, might be useful in correcting a possible misconception of what such truth would amount to. My question in this lecture is whether the image is well suited to a similar employment in the field of ethics.

In connection with the prospects for crediting ethical statements or judgments with truth, David Wiggins has pressed a distinction between what he calls 'valuations', on the one hand, and 'directives or deliberative (or practical) judgements', on the other. ${ }^{2}$ It is in relation to the former category that the attribution of truth is most immediately attractive: valuations are not easily assimilated to, for instance, decisions what to do, but naturally strike us as correct or incorrect according to whether or not they accurately delineate the values that are to be found in their subject matter. This feature of valuations makes them also the most immediately tempting field for an application of the idea of projection: the phenomenology that makes the attribution of truth attractive can seem well explained as the upshot of a projection of what Hume would call 'sentiments' on to their objects. Without prejudice to the possibility of extending the discussion to Wiggins's other category, for the purposes of this lecture I shall generally have valuations in mind.

In the case of the supposedly absolute or intrinsic property of disgustingness, what projection leads to is error: one takes what one in fact spreads on to the external world to be something one finds in the world on to which one spreads it, something that is there anyway - that is, there independently of human or sentient responses to things. It may seem that any projective thinking must be metaphysically erroneous in this way: the associated 'error theory' in ethics was embraced, as is well known, by J. L. Mackic. ${ }^{3}$ But we have to take note of a different use of the image of projection, which has been elaborated in a number of 
writings by Simon Blackburn. The position Blackburn describes, and recommends for ethics in particular, is what he calls 'quasi-realism'. This aims to demonstrate that, starting from the claim that a mode of thinking (valuation in our particular case) is projective, we can see how it can, without confusion, exemplify nevertheless all the twists of thought and speech that might seem to signal a fully realist metaphysic, although-since they are now provided for within a projectivist framework-it must be a mistake to suppose they signal any such thing. ${ }^{4}$ According to Hume, when our 'taste' is projected on to the world, it 'raises in a manner a new creation'. ${ }^{5}$ Blackburn's proposal, in effect, is that this 'new creation' can be sufficiently robust to underwrite the presence of the trappings of realism, so to speak, in thought and speech which is correctly understood as projective; and that participants in such thought and speech need not be led by those elements of it into missing its projective nature. We can be clear, even as we suppose that our judgments accurately delineate the contours of reality, that it is only the 'new creation', a product of projection, that is in question.

2. A tension arises in Blackburn's separation of projectivism from an error theory. (I mention this not to make it a problem for him, but to bring out a point that will be important in what follows.) To begin with at least, it is natural to put the projectivist thought, and Blackburn characteristically does put it, by saying that ethical commitments should not be understood as having truth-conditions. That would represent ethical remarks as statements about how things are, and according to projectivism they should be taken rather to express attitudes or sentiments. ${ }^{6}$ But quasi-realism is supposed to make room for all the trappings of realism, including the idea that the notion of truth applies after all to ethical remarks. In that case, the original sharp contrast between putting forward a candidate for being true and expressing an attitude or sentiment cannot be right: a remark that expresses an attitude can also affirm a truth. Does this mean that projectivist quasi-realism is selfdefeating? 7

Not if we can distinguish what the projectivist starting-point rejects from what the quasi-realist conclusion establishes as acceptable. It may be tempting to suppose that this can be done only if we discern two different notions of truth, one to figure in the projectivist denial that ethical statements can be true, and the other to figure in the quasi-realist reinstatement of ethical truth. ${ }^{8}$ However, this is not how Blackburn resolves the tension. ${ }^{9}$ What Blackburn does-and this is centrally important to the point I want to make-is to contrast an unearned appeal 
to the notion of truth, which is what the projectivist rejects, with an eamed right to the use of the notion, which is what the quasi-realist reinstates. The point about the application of the notion of truth that quasi-realism is supposed to make available is that we do not merely help ourselves to it, but work for it.

The contrast - the unearned employment of the notion of truth that projectivism rejects-is a position that expands reality by mere postulation, beyond what the projectivist is comfortable with, to include an extra population of distinctively value-involving states of affairs or facts. Corresponding to this, it purports to equip us with special cognitive faculties by whose exercise we become aware of this special field of knowable fact. These special cognitive faculties are vaguely assimilated to the senses, but no detailed account can be given of how they operate, such as might make it clear to us-as clear as it is in the case of the senses-how their exercise affords us access to the relevant range of circumstances. The assimilation to the senses gives this intuitionistic position the superficial appearance of offering an epistemology of our access to valuational truth, but there is no substance bchind this appearance.

How does projectivism improve on this rather clearly disreputable position?

The basic projectivist idea is that ethical remarks express not mysterious 'cognizings' of valuational facts, but attitudes. Now if that were the whole story, there would not be much prospect of a substantial notion of truth; think of the practice of expressing one's attitudes to various flavours of ice cream. But there is an extra ingredient to the story, which quasi-realism exploits. The attitudes are the upshot of sensibilities: that is, propensities to form various attitudes in response to various features of situations. Ethical sensibilities are themselves subject to attitudes of approbation or disapprobation; and-that is the crucial thing-these attitudes to sensibilities are a matter for argument and criticism. ${ }^{10}$ We are not content simply to go along with the flow of our sensibilities as they stand, regardless of how they fare under critical scrutiny; and we are not at liberty to rank sensibilities at random and still be taken seriously as participants in ethical discussion. Truth, in a remark that has to be understood in the first instance as expressive of an attitude, can now be explained in terms of the fact that the sensibility from which the attitude issues stands up to the appropriate kind of criticism.

To complete the picture, we should need an account of the nature of the criticism to which ethical sensibilities are subject. In part the critical 
assessment in question is formal, involving requirements like consistency. But there are also substantive constraints on whether a sensibility is acceptable: these derive-so Blackburn seems to suggest-from the function of ethical thought and speech in helping to secure such goods as social order and co-operation. " This sketch will serve for the present: as we shall see, a crucial issue opens up when one sets out to be less schematic.

3. It is hard to imagine that anyone would explicitly deny that if truth in ethics is available, it needs to be earned. It scems clear, moreover, that one would be deceiving oneself if one thought that those vague analogies with perception amounted to earning it. If the idea that truth must be earned is located as, precisely, a corrective to the unhelpful intuitionistic realism that Blackburn is primarily concerned to reject, it can seem to establish a conclusion about a metaphysical basis on which ethical truth must be worked for: realism shirks the obligation, and the clear alternative is projectivism. But it is questionable whether that is the right setting in which to place the idea that truth must be earned.

Consider a view of the current predicament of ethics on the lines of Alasdair MacIntyre's in After Virtue. ${ }^{12}$ According to MacIntyre, the description of ethical language given by C. L. Stevenson-although it is not, as Stevenson claimed, a correct description of ethical language as such - has come to be true of the ethical language that is actually at our disposal. One crucial ingredient of Stevenson's picture is the implication that no substantial distinction can be drawn among methods of inducing people to change their minds on ethical matters, between making reasons available to them on the one hand and manipulating them in ways that have nothing in particular to do with rationality on the other. I do not want to go into the question whether MacIntyre is right in contending that we now lack the means to draw such distinctions; the point is that if he is right, then clearly there is no prospect of achieving, in ethical thought with its present conceptual resources, anything that we could count as truth in any serious sense. No doubt it is always possible for anyone to use ' $\mathrm{lt}$ is true that...' as an indication of willingness on his own part to affirm whatever follows 'that'. But if MacIntyre's Stevensonian picture is correct, we lack what a more substantial notion of truth seems plainly to requirc, a conception of better and worse ways to think about ethical questions which connects with the idea that there are reasons for being of a certain mind on a question, in contrast with the idea that there is nothing to ethical 
thinking but rationally arbitrary subjective stances and whatever power relations might be exploited to shift people's ethical allegiances. ${ }^{13}$

Earning the notion of truth, in the face of this sort of suggestion, would thus be a matter of arguing that we do after all have at our disposal a conception of reasons for ethical thinking which is sufficiently rich and substantial to mark off rationally induced improvements in ethical stances from alterations induced by merely manipulative persuasion.

Positions like MacIntyre's suggest a quite different context for the thought that the availability of truth in ethics is something that it would take work to establish. The problem about truth in ethics, viewed in this context, is not that it fails to be as the intuitionist realist supposes, so that cstablishing its availability requires a different metaphysical basis. The problem is that a question is raised whether our equipment for thinking ethically is suited only for mere attitudinizing - whether our ethical concepts are too sparse and crude for ethical thought to seem an exercise of reason, as it must if there is to be room in it for a substantial notion of truth. ${ }^{14}$ It is really not clear why addressing a problem of this sort should seem to requirc a metaphysical move at all.

4. It may still seem that, even if earning truth in the face of this sort of challenge to its availability requires something other than an explicitly metaphysical move, namcly vindicating the richness and robustness of the conception of reasons for ethical judgments that our conceptual resources equip us with, nevertheless, as soon as we concede that attaining truth is not simply a matter of 'cognizing' valuational facts, we must have implicitly adopted a projectivist metaphysic. This appearance reflects an assumption that, at the metaphysical level, there are just two options: projectivism and the unattractive intuitionistic realism that populates reality with mysterious extra features and merely goes through the motions of supplying an epistemology for our supposed access to them. But the assumption is questionable.

The point of the image of projection is to explain certain seeming features of reality as reflections of our subjective responses to a world that really contains no such features. Now this explanatory direction scems to require a corresponding priority, in the order of understanding, between the projected response and the apparent feature: we ought to be able to focus our thought on the response without needing to exploit the concept of the apparent feature that is supposed to result from projecting the response. In the sort of case I cited at the beginning, it is plausible that this requirement is met: disgust, or nausea, we can plausibly 
suppose, are self-contained psychological items, conceptualizable without any need to appeal to any projected properties of disgustingness or nauseatingness. (No doubt a full explanation of the psychological phenomena would group things together in terms of their tendency to produce those responses, but those tendencies are not properties that need to be explained as projections of the responses.) The question, now, is this: if, in connection with some range of concepts whose application engages distinctive aspects of our subjective make-up in the sort of way that seems characteristic of evaluative concepts, we reject the kind of realism that construes subjective responses as perceptions of associated features of reality and does no work towards earning truth, are we entitled to assume that the responses enjoy this kind of explanatory priority, as projectivism seems to require?

It may help to consider a non-ethical case in which an intuitionistic realism is obviously unattractive, and in which Blackburn proceeds as if projectivism is obviously correct: the case of the comic or funny. To begin with at least, this looks like a good field for a projective account. But what exactly is it that we are to conceive as projected on to the world so as to give rise to our idea that things are funny? 'An inclination to laugh' is not a satisfactory answer ${ }^{15}$ : projecting an inclination to laugh would not necessarily yield an apparent instance of the comic, since laughter can signal, for instance, embarrassment just as well as amusement. Perhaps the right response cannot be identified except as amusement; and perhaps amusement cannot be understood except as finding something comic. I need not take a view on whether this is correct. But if it is correct, there is a serious question whether we can really explain the idea of something's being comic as a projection of that response. The suggestion is that there is no self-contained prior fact of our subjective lives that could enter into a projective account of the relevant way of thinking: in the only relevant response, the conceptual apparatus that figures in the relevant way of thinking is already in play. No doubt the propensity to laugh is in some sense a self-contained prior psychological fact. But differentiating some exercises of that unspecific propensity as cases of amusement is something we have to learn, and if the suggestion is correct, this learning is indistinguishable from coming to find some things comic. Surely it undermines a projective account of a concept if we cannot home in on the subjective state whose projection is supposed to result in the seeming feature of reality in question without the aid of the concept of that feature, the concept that was to be projectively explained. And surely this scepticism cannot tend in the direction of a relapse into the intuitionistic sort of realism. 
Blackburn himself is remarkably casual about this. I know only one place where he discusses the question whether this kind of consideration poses a problem for projectivism; and in that place he simply asserts that there is no problem for projectivism if the only way to describe a supposedly projected subjective response is in terms of seeming to find the supposed upshot of projecting it in something one confronts. ${ }^{16}$ I think this reflects the assumption I mentioned earlier, that if we are not realists of the unsatisfactorily intuitionistic sort then we cannot but be projectivists.

Blackburn's view of the available options is well summed up in these words of his (they apply to morality in particular, but the structure is quite general):

\footnotetext{
The projectivist holds that our nature as moralists is well explained by regarding us as reacting to a reality which contains nothing in the way of values, duties, rights and so forth; a realist thinks it is well explained only by sceing us as able to perceive, cognize, intuit, an independent moral reality. He holds that the moral features of things are the parents of our sentiments, whereas the Humcan holds that they are their children. ${ }^{37}$
}

Realism here is the unsatisfactory position that helps itsclf to an unearned notion of truth. So if the choice is the one Blackburn offers in this passage, it seems compulsory to ope for regarding the 'features of things' that are in question as children of our sentiments rather than their parents. There is no room to raise a problem about whether the sentiments have the requisite explanatory independence. But why do we have to limit ourselves to those two options? What about a position which says that the extra features are neither parents nor children of our sentiments, but-if we must find an apt metaphor from the field of kinship relations-siblings? ${ }^{18}$ Such a view would be appropriate for amusement and the comic, if that case is as I have suggested it might be. Denying that the extra features are prior to the relevant sentiments, such a view distances itself from the idea that they belong, mysteriously, in a reality that is wholly independent of our subjectivity and set over against it. It docs not follow that the sentiments have a priority. If there is no comprehending the right sentiments independently of the concepts of the relevant extra features, a no-priority view is surcly indicated. There are two possible ways of not being an intuitionistic realist, and the image of projection really fits only one of them.

In the case of the comic, the threat in face of which it would be necessary to earn truth-if one wanted to-would not be that any persuasion seems indistinguishable from manipulation; argument is not 
an important ingredient in that part of our lives. (The attempt to persuade someone that something is funny is typically self-defeating.) But there is a sameness underlying this difference. In both cases, the threat to a substantial notion of truth lies in the idea that there is nothing really to choose between different sensibilities, and that any convergence is best thought of as a mere coincidence of subjectivities rather than agreement on a range of truths $\rightarrow$ the sort of view that would be natural if everyone came to prefer one flavour of ice cream to any other. And in both cases, the threatening thought can be put like this: different sensibilities cannot be ranked according to whether there are better reasons for one sensibility's response than another's. Whether or not the sensibilities are conceived as typically altered by argument, so that the issue can be whether persuading someone counts as giving him reasons to change his mind, the challenge can be put as a query whether a mode of thought that engages subjective responses allows for a sufficiently substantial conception of reasons for exercises of it to be capable of truth.

The interest of the no-priority view, now, is that it opens up the possibility that it might be respectable to use the apparently worlddescribing conceptual resources with which we articulate our responses, in earning truth in one of the relevant areas. Blackburn's simpler structure of options suggests that we must deny ourselves those resources, on pain of lapsing back into a bald intuitionism. A serious projective quasi-realism about the comic would construct a conception of what it is for things to be really funny on the basis of principles for ranking senses of humour which would have to be established from outside the propensity to find things funny. The contrasting idea would be that we might regard our conception of greater and less refinement and discrimination in senses of humour as derivative from an understanding of what it is for things to be really funny: something we can acceptably aim to elaborate from within the propensity to find things funny. The concept of the comic is not a device for a rationally isolated grouping of items, things whose satisfaction of it we take to be simply a matter of their eliciting the appropriate reaction from us; having the concept involves at least inklings of a place it occupies in a rationally interconnected scheme of concepts, and we should aim to exploit such inklings in working out an aesthetic, so to speak, of humour. A ranking of sensibilities would flow from that, rather than being independently constructed (from what materials? ${ }^{19}$ ) and used to deliver verdicts on when things are really comic. Of course we might not be able to squeeze much in the way of rankings of senses of humour out of our understand- 
ing of the funny. And anything on these lines that we did come up with would be liable, as such constructions always are, to accusations of fraud, on behalf of people whose senses of humour we represented as blunter than they might be. We would need to take great care to be sure that we were not merely projectively conferring a bogus objectivity on the deliverances of a sensibility that was in fact rationally on a par with any other. But, although we must of course acknowledge the risks and do our best to guard against them, we would not be guaranteed to fall into self-deception of this sort, simply by virtuc of working from within.

The no-priority view allows, then, that it might be possible to do something recognizable as earning truth by focusing on the funny itself. The idea of what is really funny need not be explained in terms of an independently established conception of what makes a sense of humour more discriminating. This contrasts with a constraint that seems to be implicit in a serious projectivism, according to which the idea of a superior discernment has to be made clear without exploiting exercises of the way of thinking which is to be explained as projective, so that it is available for use in certifying some such exercises as (quasi-realistically) true.

Analogously in the ethical case; here again, the possibility of the nopriority view brings out that we do not need to choose between, on the one hand, lapsing into intuitionism-simply helping ourselves to truth-and, on the other, disallowing ourselves, in earning truth, the conceptual equipment that projectivism sees as the product of projection. Earning truth is a matter of supplying something that does satisfactorily what is merely pretended by the bogus epistemology of intuitionism. Instead of a vague attempt to borrow the epistemological credentials of the idea of perception, the position I am describing aims, quite differently, at an epistemology that centres on the notion of susceptibility to reasons. The threat to truth is from the thought that there is not enough substance to our conception of reasons for cthical stances. When we try to meet this threat, there is no reason not to appeal to all the resources at our disposal, including all the ethical concepts that we can lay our hands on, so long as they survive critical scrutiny; and there need be no basis for critical scrutiny of one ethical concept except others, so the necessary scrutiny does not involve stepping outside the point of view constituted by an ethical sensibility.

Notice that this does not make it a foregone conclusion that the threat will be satisfactorily met: Macintyre's picture of our present predicament, for instance, cannot be ruled out without actually looking into the resources we still have. Aiming to meet the threat from within is 
not helping ourselves to ethical truth in the manner of an intuitionistic realism; and it would be quite wrong to suppose that it is helping ourselves to ethical truth in the different sense that the issue is prejudged in favour of truth being attainable.

5. Blackburn has purported to respond to the suggestion that truth in ethics might be earned from within ethical thinking, and similarly in other areas where an issue about projection arises. His claim is that such a suggestion merely shirks a plainly necessary explanatory task: one in which

we try to place the activity of moralizing, or the reaction of finding things funny ... In particular we try to fit our commitments in these areas into a melaphysical understanding of the kinds of fact the world contains: a metaphysical view which can properly be hostile to an unanalysed and sui generis area of moral or humorous ... facts. And relative to this interest, answers which merely cite the truth of various such verdicts are quite beside the point. This ... is because there is no theory connecting these truths to devices whereby we know about them-in other words, no way of protecting our right to [conditionals of the form 'If it hadn't been the case that $p$, I would not be committed to $\left.p^{\prime}\right] .20$

This passage raises several questions. I shall end this lecture by making three points about it.

First, note how the passage still strikes the note of theft as against honest toil, as if the target were still the kind of intuitionism that merely helps itself to a novel range of facts. This looks quite unwarranted once it is clear that there are three positions and not just two. The suggestion is not that we 'merely cite the truth'-presumably alleged to be detected by some mysterious quasi-sensory capacities-of specific ethical verdicts, or judgments to the effect that something is funny. The aim is to give an account of how such verdicts and judgments are located in the appropriate region of the space of reasons. No particular verdict or judgment would be a sacrosanct starting-point, supposedly immune to critical scrutiny, in our earning the right to claim that some such verdicts or judgments stand a chance of being true. That is not at all to say that we must earn that right from an initial position in which all such verdicts or judgments are suspended at once, as in the projectivist picture of a range of responses to a world that does not contain values or instances of the comic.

The second point relates to the 'metaphysical understanding' that Blackburn mentions. This fixes an inventory of 'the kinds of fact the world contains'. It fixes also, in parallel, a conception of the kinds of cognitive occurrence that can constitute access to facts: nothing will 
serve except what can be conceived in terms of the impact on us of the world as the 'metaphysical understanding' understands it. That is why one is not allowed to count as protecting one's right to a conditional of the form 'If it had not been the case that $p$, I would not have become committed to the belief that $p^{\prime}$ if one establishes that one would not have arrived at the belief that $p$ had it not been for good reasons for it, with the excellence of the reasons vindicated from within the relevant way of thinking.

But how good are the credentials of a 'metaphysical understanding' that blankly excludes values and instances of the comic from the world in advance of any philosophical enquiry into truth?21 Surely if the history of philosophical reflection on the correspondence theory of truth has taught us anything, it is that there is ground for suspicion of the idea that we have some way of telling what can count as a fact, prior to and independent of asking what forms of words might count as expressing truths, so that a conception of facts could exert some leverage in the investigation of truth. We have no point of vantage on the question what can be the case, that is, what can be a fact, external to the modes of thought and speech we know our way around in, with whatever understanding of what counts as better and worse execution of them our mastery of them can give us. If there is enough substance to that understanding to enable us to rule out positions like MacIntyre's with a clear conscience, that is what it is for truth to be attainable in such thought and speech, and so much the worse for any prior 'metaphysical understanding' which holds that there cannot be facts of that kind. ${ }^{22}$ It is a matter for diagnosis and exorcism, not something that can be allowed without further ado to be a good starting-point for a philosophy of ethics or humour. To reiterate the first point, we need not be frightened out of this line by the bogey of 'an unanalysed and sui generis area of moral or humorous ... facts'. That is what one gets if one accepts a familiar 'metaphysical understanding' - one which is in fact quite dubious even in the areas where it is most tempting-with its picture of facts and our access to them, and then tries to accommodatc exercises of ethical sensibilities or senses of humour within its framework; but that was never the proposal.

The third point is about 'placing' ethics or humour. I have been suggesting that an undefended 'metaphysical understanding' cannot impose binding intellectual obligations on anyone. But that is not to say there are no good questions in this general vicinity. Consider the world as natural science describes it. It is plausible (although not beyond dispute) that that 'world' would not contain moral values or instances of 
the comic. (This is no concession to the 'metaphysical understanding': what is missing is a reason to suppose that natural science has a foundational status in philosophical reflection about truth-that there can be no facts other than those that would figure in a scientific understanding of the world.) Now there is no reason not to raise the question how ethics or humour relate to the scientifically useful truth about the worid and our dealings with it. There is no reason to dispute that a good answer to such questions can contribute to our making ourselves intelligible to ourselves in a way that we ought to find desirable. Finding things funny, for instance, can seem, from a certain fully intelligible perspective, a peculiar and even mysterious aspect of our lives, quite unlike, say, being able to tell what shapes things have, or even what colours things have. Anything that alleviated this sense of mystery would be welcome, and it would be anti-intellectual or obscurantist to deny that. What is unclear, however, is why it seems so obvious to Blackburn that this kind of consideration supports projectivism. No doubt reflections about the benefits of co-operation and social order go some distance towards 'placing' ethics-making it intelligible that we inculcate ethical sensibilities in our young, trying to give ethics the importance to them that we believe is proper. (It is not at all obvious what might play an analogous role with senses of humour.) But we do not need to suppose that such 'placing' functions by allowing us to make sense of a range of subjective responses to a world that contains nothing valuable, or funny-responses that we can then see as projected on to that world so as to generate the familiar appearances. What we 'place' need not be the sort of sentiments that can be regarded as parents of apparent features: it may be pairs of sentiments and features reciprocally related-siblings rather than parents and children.

There is surely something right about the Humean idea of a 'new creation'-the idea of a range of seeming states of affairs which would not be as they are if it were not for the distinctive affective colouration of our subjectivity. What does not follow is that the seeming states of affairs can be understood as creatures of independently intelligible operations of our affective nature. These seeming objectivities need not be a shadow or reflection of a self-contained subjectivity: understanding the genesis of the 'new creation' may be understanding an interlocking complex of subjective and objective, of response and feature responded to. And in that case it is a mistake to think we can illuminate the metaphysics of these matters by appealing to the image of projection. 


\section{Notes}

1. See A Treatise of Human Nature 1. iii. 14.

2. See his 'Truth, Invention, and the Meaning of Life', Proceedings of the British Acadmy lxii (1976), 332-78, al pp. 338-9.

3. See Chapter 1 of his Ethics: Inventing Right and Wrong (Penguin Books, Harmonds. worth, 1977).

4. Among many other writings, see Chapters 5 and 6 of Blackburn's Spreading the Word (Clarendon Press, Oxford, 1984).

5. An Enquiry Concerning the Briuciples of Morals, Appendix I.

6. See, e.g., Spreading the Word, pp. 167-71.

7. Blackburn raises the question whether 'a projective approach is too good to be truc' at p. 219 .

8. See Crispin Wright, 'Realism, Anti-Realism, Irrealism, Quasi-Rcalism', forthcoming in an issue of Midwest Studies in Philosophy devoted to realism.

9. See p. 257: 'Does this make moral commitments true in the same sense as others, or only in a different sense? I do not greatly commend the question.'

10. See Spreading the Word, p. 194.

11. See, e. g., pp. 192, 197. I think Blackburn would regard Hume's treatment of the artificial virtues as a model of the kind of thing that would be required in a full version of the quasi-realist project, constructing truth out of an account of how projective thinking can allow for a substantial notion of beller and worse ways of doing it.

12. Duckworth, London, 1981.

13. I am not suggesting that any ethical thought and language of which an account which is in some sense emotivist is true must dissolve such distinctions: compare Spreading the Word, p. 197. (I have not questioned that ethical thought and speech engages our affective nature, and 1 suppose that is an emotivist insight.) But Stevenson's account does dissolve such distinctions; so it alfords a good picture of a kind of threat in face of which earning truth should seen a good thing to attempt. (If MacIntyre is right, carning truth would involve a conceptual reform.)

14. This requires me to take issuc with Blackburn when he says things like the following (p. 181 of 'Reply: Rule-Following and Moral Realism'): 'Of course, it is true that our reactions are 'simply felt' and, in a sense, not rationally explicable. But we should not be 100 worried about renson here. In general, reason follows where truth leads. 'By my lights this is the wrong way round. If we could not convince ourselves that our rankings of sensibilities were capable of being grounded in reason (as Blackburn's appeals, when it suits, to argument and criticism suggest they are), there would not be any reason to suppose that we had regained an application for the notion of truth.

15. Compare Blackburn's 'Frrors and the Phenomenology of Value', in Ted Honderich, ed., Morality and Objectivity (Routledge and Kegan Paul, London, 1985). pp. 1-22, at p. 9.

16. This is at pp. 180- 1 of 'Opinions and Chances', in D. H. Mellor, ed., Prospects for Pragmatism (Cambridge University Press, Cambridge, 1980), pp. 175-96. Blackburn makes the point that it would not be surprising, given a projectivist view, that 'our best vocabulary for identifying the reaction should be the familiar one using the predicates we apply to the world we have spread'. 'This seens right: once we have done the spreading. the resulting way of talking will no doubt seem more natural to us than any other. But that is not the same as saying that there is no alternative way of identifying the responsc; if there is no alternative way, then there is no way of saying what has happened, in detail, in terms of the image of projection, and it is olsscure why we should allow that to be consistent with projectivism.

17. 'Reply: Rule-Following and Moral Realism', in Steven Holtzman and Christopher Leich, eds., Wittgenstein: To follow a Rule (Routledge and Kegan Paul, London, 
1981), pp. 163-87, at pp. 164-5. It may be worth mentioning in passing that the idea of rights as children of our sentiments seems an over-simplification of Hume's view.

18. See David Wiggins, 'Truth, Invention, and the Meaning of Life', at p. 348; and for an elaboration of the thought there expressed that 'an adequate accoum of these matters will have to treat psychological states and their objects as equal and reciprocal partners', see now 'A Sensible Subjectivism?', in his Needs, Values, Deliberation and Truth (Basil Blackwell, Oxford, 1987).

19. This is a serious question for anyone who is sympathetic to a quasi-realist projectivism about the comic. Much of what is ordinarily appealed to in ranking objects for amusement is suitably external but just for that reason not obviously relevant to this issuc: for instance much humour that one may deplore as being 'in bad taste' (usually on moralistic grounds) is not thereby shown not to be extremely funny. It seems highly implausible that we could extract out of the function of the sense of humour (if we knew it) something that would even seem to do the sort of work in a quasi-realist ranking of sensibilities that Blackburn seems to suggest is done in the ethical case by the function of ethical thinking.

20. 'Errors and the Phenomenology of Value', pp. 17-8: the matcrial in square brackets is supplied from p. 16.

21. Blackburn is extraordinarily unconcerned with this question. See Spreading the Word, p. 39, where 'the best philosophical problems' are said to arise when 'we get a sense of what the world is like, what it must be like', and cannot find room in it for this or that which we are loath to give up: for instance, 'consciousness, agency, causation, or valuc'. The question where we get this sense, and what its credentials might be, is not raised. Similarly at p. 146: 'Once such doubts are felt-motivated in whatever way-a number of attitudes are possible.' Again there is the striking lack of concern with the origin of the doubts, and this leaves no room for addressing the question of their merits. It is as if any bit of philosophy that comes naturally to us must be all right, ahead of any inquiry into why it comes naturally to us. (In my 'Values and Secondary Qualities', in Honderich, ed., op. cit., pp. 110-129, I consider and reject the suggestion that the favouritism of the 'metaphysical understanding' might be defended on the basis of a conception of the real as what is explanatorily indispensable. Blackburn's purported response, in 'Errors and the Phenomenology of Value', pp. 17-18, still takes the 'metaphysical understanding' not to need defending: the response does not make contact with its purported target.)

22. Blackburn considers (see Spreading the Word, p. 236) the thesis that 'there is no way in which any mind can step back from its own system of belief, survey without its benefit a reality the system aims to depict, and discover whether it is doing well or badly'. I am not sure I understand his attitude to this thesis. In the chapter from which I have quoted those words, he considers (as in the passage under discussion in my text) only 'correspondence conditionals' with directly causal underpinnings-cases where we can take quite literally the idea of reality making an impact on us. It would surely be a mistake to suppose that when we cite such causal underpinnings for the idea that we are capable of attaining the truth in some area, we are somehow managing after all to step outside reliance on the best we can do, from within our 'system of belief, to afford reasons for bits of it. And one might think this thought ought to neutralize 'correspondence conditionals' in particular: that is just one shape that rationally underwritten 'correspondence conditionals' can take. Blackburn, however, writes (pp. 247-8) as if such a thought involves a 'gestalt-switch' akin to ldealism, and in competition with ascribing to objects and facts 'their independence of us and our believings'. It seems to me quite clear that there is no competition here. I am accordingly led to wonder if Blackburn is, in some submerged way, conceiving the causal impact on us of some facts as a way in which after all the World itself-what we would like to get a glimpse of head en, if we could only 'step back' - penetrates the veil of our 'system of belief and gets through to us. 
The following lectures have been published in individual pamphlet form and may be obtained from the Department at a price of one dollar and fifty cents each.

•1961. "The Idea of Man-An Outline of Philosophical Anthropology." By José Ferrater Mora, Professor of Philosophy, Bryn Mawr College.

1962. "Changes in Events and Changes in Things."

By A. N. Prior, Professor of Philosophy, University of Manchester.

" 1963. "Moral Philosophy and the Analysis of Language.",

By Richard B. Brandt, Professor of Philosophy, Swarthmore College.

• $†$ 1964. "Human Freedom and the Self."

By Roderick M. Chisholm, Professor of Philosophy, Brown University.

†1965. "Freedom of Mind."

By Stuart Hampshire, Professor of Philosophy, Princeton University.

"†1966. "Some Beliefs about Justice."

By William K. Frankena, Professor of Philosophy, University of Michigan.

†1967. "Form and Content in Ethical Theory."

By Wilfrid Sellars, Professor of Philosophy, University of Pittsburgh.

†1968. "The Systematic Unity of Value."

By J. N. Findlay, Clark Professor of Philosophy, Yale University.

1969. "Buber and Buberism-A Critical Evaluation."

By Paul Edwards, Professor of Philosophy, Brooklyn College of the City University of New York.

1971. "What Actually Happened."

By P. H. Nowell-Smith, Professor of Philosophy, York University.

†1972. “Moral Rationality."

By Alan Gewirth, Professor of Philosophy, University of Chicago.

$\dagger 1973$. "Reflections on Evil."

By Albert Hofstadter, Professor of Philosophy, University of California, Santa Cruz.

$\dagger † 1974$. "What is Dialectical?"

By Paul Ricoeur, Professor of Philosophy, University of Paris and University of Chicago.

$\dagger \uparrow 1975$. "Some Confusions About Subjectivity."

By R. M. Hare, White's Professor of Moral Philosophy at Oxford University and Fellow of Corpus Christi College.

1976. "Self-Defense and Rights."

By Judith Jarvis Thomson, Professor of Philosophy, Massachusetts Institute of Technology.

1977. "What is Humanism?"

By Georg Henrik von Wright, Research Professor of Philosophy, The Academy of Finland.

1978. "Moral Relativism."

By Philippa Foot, Senior Research Fellow, Somerville College, Oxford; and Professor of Philosophy, University of California, Los Angeles.

1979. "The Idea of the Obscene."

By Joel Feinberg, Professor of Philosophy, University of Arizona.

1980. "Goods Beyond Price and Other Apparent Anachronisms."

By Warner Wick, Professor of Philosophy, University of Chicago.

1981. "Morality, Property and Slavery."

By Alan Donagan, Professor of Philosophy, University of Chicago.

1982. "Expressing Evaluations."

By Donald Davidson, Professor of Philosophy, University of California, Berkeley.

- Pamphlet out of print.

t Reprinted in Freedom and Morality.

t1 Printed only in Freedom and Morality. 
1983. "How Not to Solve Ethical Problems."

By Hilary Putnam, Professor of Philosophy, Harvard University.

1984. "Is Patriotism a Virtue?"

By Alasdair MacIntyre, W. Alton Jones Professor of Philosophy, Vanderbilt University.

1985. "How Free Does the Will Need to Be?"

By Bernard Williams, Provost of King's College Cambridge.

1986. "Moral Agent and Impartial Spectator."

By Gilbert Harman, Professor of Philosophy, Princeton University.

A Volume of Lindley Leotures

Dollvered at the Univeralty of Kaneas

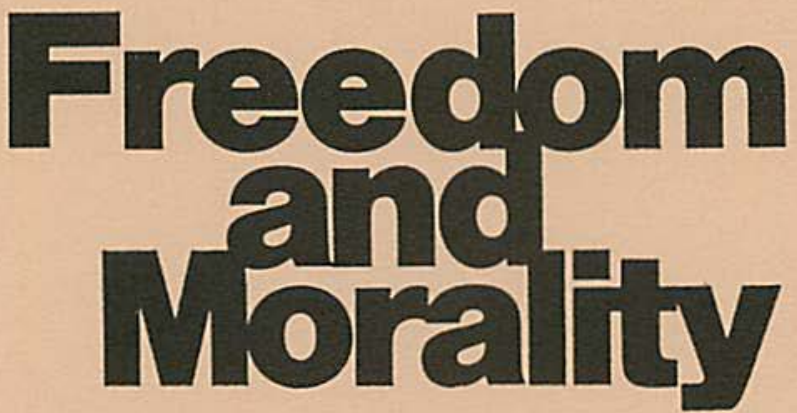

Rlohard B. Brandt Moral Philosophy and the Analysis of Language

Rodorlok M. Chlaholm Human Fieodom and the Selt

Stuart Hampehiro Fieedom of Mind

WIIIlam K. Frankena

Some Betiets about Justice

\section{Wilfrid Sollare}

Form and Conient in Eincal theory
J. M. Findlay The Sysiemalic Unity of Value

Alan Qowirth Moral Rationality

Albert Hofatadter Feflectione on EvI

Paul Rlcoour What is Diarectican

\section{R. M. Hare}

Some Contusions abou subjectivity

Edied with an introduction oy John Bricke
The volume can be purchased for $\$ 6.00$ from the Library Sales Office, University of Kansas Libraries, Lawrence, Kansas (U.S.A.) 66045. Please include a $50^{\circ}$ handling fee, $75^{\circ}$ outside the United States. 